\title{
TRUST(S) AND INTENTION IN RESOLVING DISPUTES OVER THE SHARED HOME
}

\section{Simone Wong, Lecturer, Kent Law School, University of Kent INTRODUCTION}

To date, the rights of unmarried home-sharers remain hotly contested, with cases like Burns $\mathrm{v}$ Burns ${ }^{1}$ and Lloyds Bank $\mathrm{v}$ Rosset $^{2}$ being subjected to heavy criticism. There has been little political will to introduce reform in this area, ${ }^{3}$ and disputes over the shared home continue to be resolved in England and Wales, as well as in Northern Ireland, under contract, property and/or trusts law, especially the common intention constructive trusts. ${ }^{4}$ However, the common intention approach remains problematic because of the need for mutuality and its focus on direct financial contributions. ${ }^{5}$ With the exception of a handful of cases such as Hammond $\mathrm{v}$ Mitchell $^{6}$ and Midland Bank v Cooke ${ }^{7}$ where a more generous broad brush approach was taken, there is little evidence of any radical deviation from the test laid down by Lord Bridge in Rosset.

In 2002, the issue of property distribution on relationship breakdown was considered by the Law Commission ${ }^{8}$ and the Law Society respectively. ${ }^{9}$ Their foci were quite different, however, accounting for the contrasting approaches taken. The Law Commission's remit was wider in that it covered home-sharers, which extended to a wider range of relationships, ${ }^{10}$ but

1 [1984] Ch.317.

2 [1991] 1 A.C. 107. In that case, Lord Bridge sets out two conditions: firstly, common intention to share, whether express or inferred; and secondly, the claimant must have acted to her detriment in reliance on that common intention. Intention may only readily be inferred from direct financial contributions towards the purchase of the property.

3 It should be noted that the Civil Partnership Bill (CPB), which provides a scheme for registering same-sex civil partnerships, was introduced to the House of Lords on 30 March 2004. The Bill was amended in the Lords to extend to family members in certain degrees of relationships. At the time of writing, the CPB has not completed its passage through Parliament. The Government has also undertaken to remove the amendments made in the Lords in order to revert the Bill to its original remit. If passed, the $\mathrm{CPB}$ would provide a property regime to registered same-sex couples only.

4 Lloyds Bank v Rosset. For Northern Ireland cases, see e.g. Re Wills (a Bankrupt), unreported, Ch. Div., 30 November 1992; Britannia Building Society v Johnston, unreported, Ch. Div, 13 May 1994.

5 See, e.g., Bottomley (1993) 20 J.L.S. 56; Eekelaar (1987) 51 Conv. 93; Gardner (1993) 109 L.Q.R. 263; Clarke (1992) 22 Fam. Law 72; Glover and Todd (1996) 16 L.S. 325; Lawson (1996) 16 L.S. 218; Halliwell (1991) 20 The Anglo-American Law Review 550; Wong (1998) 18 L.S. 369; Wong (1999) 7(1) F.L.S. 47.

6 [1991] 1 W.L.R. 1127.

7 [1995] 4 All E.R. 562.

8 Law Commission, Sharing Homes: A Discussion Paper Law Com. No. 278 (2002).

9 Law Society, Cohabitation: The Case for Clear Law (2002).

10 Law Commission, op. cit., n. 8 at para.1.1. The Law Commission stated that its review covered a broad range of people, including friends and relatives who 
narrower since it focused only on property rights over the shared home. The Law Society, on the other hand, focused on cohabitation and the rights and obligations of cohabitees. Given the existing difficulties faced by cohabitees under the common law, the Law Society proposed a form of registration for same-sex relationships, leaving opposite-sex and unregistered same-sex cohabitation to be governed by a presumptive system. Its putative model provided courts with powers to make property adjustment orders by taking a "fair account" of the economic advantages and disadvantages of the parties. ${ }^{11}$ By contrast, the Law Commission attempted a contributions-based property law model, which was ultimately rejected for a variety of reasons. ${ }^{12}$ Moreover, notwithstanding the problems posed by the intention requirement and its focus on direct financial contributions, the Law Commission further concluded that intention remained relevant to the determination of disputes between home-sharers and that trusts law was sufficiently flexible to adequately deal with such disputes. ${ }^{13}$

However, the oft-cited reasons for rejecting the common intention approach are, firstly, the need for intention and secondly, for such intention to be "common". To overcome the existing difficulties, the Law Commission proposed the expansion of the range of qualifying contributions to found the necessary common intention. ${ }^{14}$ It is submitted that such an expansion is simply a cosmetic way of resolving the difficulties surrounding the common intention approach. It fails to address the doctrinal issues that lie at the heart of the common intention approach and upon which the criticisms are based. For instance, while accepting that the parties' intention is important, the Law Commission does not grapple with the crucial question of how we should be thinking about "intention" and whether it should remain one "common" to both parties. It also prompts the question of whether "intention" is relevant to all, or only some, of the equitable doctrines applied in the resolution of these disputes. There presently appears to be some divergence between the common intention/rights-based approach and other remedy-based approaches such as estoppel and unconscionability, which has been adopted in Australia. ${ }^{15}$

shared a home as well as unmarried and married couples (except on the breakdown of marriage).

11 Law Society, op. cit., n.9 at paras.101-102. The principle of "fair account" relied upon by the Law Society is in fact lifted from s.9(1)(b) of the Family Law (Scotland) Act 1985.

12 Law Commission, op. cit., n.8, Part III. Although the scheme provided for recognition of both financial and non-financial contributions, the Commission argued that the very nature of a contributions-based approach would bring about less flexibility, leaving courts with less discretion and room for manoeuvre than under the existing equitable doctrines.

13 ibid., at para.4.24.

14 ibid., at paras.4.25-4.26. The main difficulty lies with the qualifying contributions necessary for inferring an intention to share. The Law Commission stated that it should be equally possible to infer an intention where indirect, especially indirect financial, contributions to the mortgage had been made.

15 A key difference between common intention and unconscionability appears to be the latter's focus on the presence of unconscionable conduct as the basis for equity's intervention and not on the parties' common intention to share. 
The paper seeks to argue that because of the institutional nature of the trust, the resolution of property disputes under a rights-based approach is inextricably linked to intention. Intention in the remedy-based approach, on the other hand, may be, but is not always, relevant. Its evidential role varies: the significance of, and the way in which we think about, intention depends on whether one adopts a rights- or remedy-based approach. It is further argued that the requirement for mutuality of intention in the rights-based approach is misconceived and should be abandoned. The continued reference to "common intention" only serves to obscure the principles upon which the trusts are being imposed in these cases. The notion of "common intention" itself has to be deconstructed and reconceptualised so as to bring greater coherency to constructive trusts. Only then can we begin to develop a better understanding of the interrelationship between intention and contributions, and expand the range of qualifying contributions on a principled basis. To do this, the paper will draw upon the plethora of literature that has provided criticisms of the common intention requirement and seek to synthesise the various arguments that have been made, with a view to providing a more coherent and principled understanding of the role of intention in constructive trusts.

\section{Rethinking Intention}

Despite the criticisms levelled at the common intention approach, little attempt has been made by the courts to address them. Consequently, while some favour its retention with appropriate modifications to the definition of "common intention", others prefer its total rejection. The alternatives proposed, however, are often inclined towards a remedy-based approach. ${ }^{16}$ For the reasons stated below, the abandonment of a rights-based approach would not be a good strategy. What is needed, rather, is greater clarity about the workings of a rights-based approach. In that respect, the Law Commission's conclusion on the importance of intention calls for a closer examination of the notion of intention and how we should be thinking about it under a rights- and a remedy-based approach.

The former will necessarily call for a narrower notion of intention because of the institutional nature of the trust. The pressing question is how that notion of intention should be formulated so as to enable the vindication of preexisting rights, without resorting to the doctrinal confusion of Rosset. By contrast, a broader notion of intention can be accommodated in a remedybased approach, since constructive trust relief is not an automatic response. This, then, raises three broad issues. The first is the wider question of whether intention should generally be relevant to the determination of beneficial ownership in a shared home. Secondly, if it is, the essence of intention and its exact role(s) needs to be specified and must be examined. This is particularly important for providing clearer distinctions between

16 E.g., the Law Commission recommended widening the range of contributions that are capable of raising the inference of an implied intention to share. $c f$. Gardner, op. cit., n.5 and Clarke, op. cit., n.5, who favour rejecting intention. Gardner's alternative, however, is a modified form of unjust enrichment based on trust and collaboration. In adopting a restitutionary analysis, the imposition of a trust is clearly a remedial response rather than a vindication of pre-existing proprietary rights. 
rights- and remedy-based approaches. Thirdly and relatedly, if a rightsbased approach were to be adopted, does intention have to be 'common' to both parties?

\section{Is intention relevant?}

As a mechanism for vindicating rights, the role of intention in a rights-based approach goes to the very question of whether the claimant has acquired any pre-existing beneficial interest in the property. As such, intention plays a more substantial evidential role than merely establishing unconscionable conduct. Greater evidentiary demands are placed on intention as it is essential to the question of whether the claimant has acquired any share in the beneficial ownership in the property. As the Law Commission observes:

"Intention is clearly important, as it would be wholly unsatisfactory if a person were to obtain a beneficial interest where it was made extremely clear that a particular contribution, by financial or other means, would not be met this way." 17

The sticking point though is that, since Rosset, the courts have insisted on the mutuality of intention, leading many commentators to argue for the rejection of the intention requirement.

While Bottomley concedes that intention may be a "fragile thing", she nevertheless argues that it remains useful to determining beneficial rights over the family home. Intention, she argues, is sufficiently flexible to enable the specific circumstances of a particular individual, in a particular social context, to be taken into account and for injustice in individual cases to be addressed. ${ }^{18}$ The problem thus lies in the courts' insistence on mutuality rather than on intention per se. More importantly, Bottomley stresses the attractions of the rights-based foundations of the common intention trust. As she explains, the rejection of a rights-based approach in favour of remedybased narratives would risk slippage into a discourse of dependency and the kind of prejudices which have often been exhibited in judicial expectations of the "good wife". 19

One obvious alternative would be a remedial approach and a compensatory model based on exchange and contribution. However, one danger of a remedial/compensatory model would be to encourage the award of remedies to women who are in relationships that seem most marriage-like and are perceived by judges as "good wives". ${ }^{20}$ A rights-based approach, on the other hand, enables the parties to engage in a "rights" discourse which provides the potential for and engagement with the notion of equality. It is "a strong narrative in which we come to the court demanding a right rather than a remedy"; it enables us to engage in a "discourse of citizenship" which demands recognition of one's right to a share in the property. ${ }^{21}$ This provides

17 Law Commission, op. cit., n.8, at para.4.24.

18 Bottomley, "Our Property in Trust: Things to Make and Do" in S. Scott-Hunt and H. Lim (eds.) Feminist Perspectives on Equity and Trusts (2001), Chap.12.

19 See also Lawson, op. cit., n.5

20 Bottomley, op. cit., n.18, at p.282.

21 ibid., at pp. 282-283. 
a more powerful litigation strategy than a remedy-based approach, which perpetuates the model of dependency. Seepage of equality rhetoric into judicial thinking can be seen in recent matrimonial cases like White $\mathrm{v}$ White, ${ }^{22}$ Cowan v Cowan ${ }^{23}$ and Lambert v Lambert. ${ }^{24}$ The courts have stated that the exercise of their adjustive powers under the Matrimonial Causes Act 1973 should be guided by the principle of non-discrimination and the notion of substantive equality. ${ }^{25}$ It remains unclear how far these principles are likely to extend to constructive trust cases. With the passage of the Human Rights Act 1998 (HRA), it is arguable that, as the emerging human rights culture develops, the courts may further build on the notion of equality when interpreting and applying the common law. ${ }^{26}$

By contrast, the adoption of a remedy-based approach is largely motivated by the difficulties associated with attempting to find an elusive "common intention". Doctrines such as unconscionability and estoppel are premised not on one or both of the parties' intention regarding the allocation of beneficial ownership, but on protecting against any unconscionable conduct that may arise if no recompense is provided. Constructive trust relief is thus a remedial response to unconscionable conduct. This then prompts the question of whether intention is obsolete in a remedy-based approach. It is submitted that intention is equally relevant but is substantively different from the intention called for in a rights-based approach. It serves to raise a presumption of the parties' reasonable expectations of sharing so as to establish evidence of unconscionable conduct. ${ }^{27}$

In unconscionability, "common intention" as understood in Rosset is clearly not a requirement. The doctrine aims at preventing one party from retaining the benefit of contributions made by the other party for the purposes of their joint relationship, which has subsequently failed without attributable blame. ${ }^{28}$ It focuses on the defendant's conduct rather than his (or the parties') intention to share and on whether there is any unconscionable denial of the claimant's beneficial interest. Unconscionability therefore encompasses a broader notion of intention. Intention forms the platform for a twofold enquiry into, firstly, the way in which the parties structure their relationship (i.e. whether they intended the relationship to be a joint partnership) and, secondly, the underlying purpose of the parties' contributions (i.e. whether these are intended for their joint benefit). As Mason C.J., Wilson and Deane JJ. state in Baumgartner v Baumgartner:

22 [2001] 1 All E.R. 1.

23 [2001] E.W.C.A. Civ.679.

24 [2003] Fam. 103.

25 Consequently, the non-financial contributions of the wife, e.g. domestic services, should not be discriminated against and given less weight than the financial contributions of the income-earning husband.

26 The extension of the principle of non-discrimination and the notion of substantive equality may be particularly pertinent to the issue of gender bias in the Rosset test and its treatment of the indirect contributions in terms of giving rise to an inference of an implied intention to share. This particular point will be dealt with in more detail below.

$27 C f$. the rights-based approach, where intention, whether express or inferred, bears the higher burden of being a condition for the creation of a valid trust.

28 Muschinski v Dodds (1985) 160 C.L.R. 583; Baumgartner v Baumgartner (1987) 164 C.L.R. 137. 
“[the parties' arrangement for the pooling of resources] was designed to ensure that their earnings would be expended for the purposes of their joint relation and for their mutual security and benefit. . . . In this context, it would be unreal and artificial to say that [the claimant] intended to make a gift to [the defendant] of so much of her earnings as were applied in payment of mortgage instalments." 29

Thus, some sort of enquiry into the parties' intentions is necessary for ascertaining the presence of unconscionable conduct. There must be some evidence of an intention that the parties' relationship should be a joint partnership, which is supported by the pooling of, preferably financial, resources. ${ }^{30}$ As Dal Pont observes, the focus on 'intention' is linked to the parties' reasonable expectations in relation to the pooling of resources and the rights they are to have in consequence. ${ }^{31}$ Intention plays a presumptive role in that the presence of an intention to structure the relationship as a joint partnership will raise a presumption of a reasonable expectation to share in the benefits to be reaped from the pooling of resources. It also raises a further presumption that any contributions made are not intended to be a gift to the other party.

As such, unconscionability has the advantage of avoiding the artificiality of searching for a "common intention", which presupposes a meeting of minds by couples engaging in arm's length discussions at the outset to reach some "agreement, arrangement or understanding" about their proprietary rights in the property. Intention is nevertheless relevant as it impacts on the question of whether the defendant's conduct is unconscionable. It addresses the broader question of the nature of the parties' relationship and the treatment of their respective contributions to the joint partnership. This in turn facilitates the determination of whether there is any unconscionable retention of such contributions. The answer will be in the affirmative where the relationship is intended to be a joint partnership, thus triggering equity's intervention.

The relevance of intention in estoppel may be more obscure. Nield, for instance, argues that one important distinction between estoppel and (common intention) constructive trusts is the role of intention. ${ }^{32}$ Reference to "common" intention in the latter accentuates the mutuality of the parties" intention, whether express or inferred. ${ }^{33}$ By contrast, the orthodox understanding of estoppel is that the defendant's intention, unilateral or otherwise, is not relevant to grounding the claim. The defendant's unilateral

29 (1987) 164 C.L.R. 137 at 139.

30 Hibberson v George (1989) 12 Fam. L.R. 725; Tory v James (1990) D.F.C. \#95095; Public Trustee v Kukula (1990) 14 Fam. L.R. 97. It should be noted that, in many of the cases, there had to be some pooling of financial resources for the claim to be successful. The lack of pooling of resources and the provision of purely domestic contributions have been less successful in grounding a claim: Arthur v Public Trustee (1988) 90 F.L.R. 203; Bryson v Bryant (1992) 29 N.S.W.L.R. 188.

31 Dal Pont (1997) 16 Aus. Bar Review 46.

32 (2003) 23 L.S. 311.

33 As will be examined below, there is however some debate as to whether mutuality is indeed required. 
conduct leading to the claimant's expectation of a share in the beneficial ownership of the property is sufficient. It is his inducement, coupled with the claimant's detrimental reliance, which forms the essential ingredients for giving rise to the claimant's equity. Equity will thus intervene to prevent the defendant from going back on his assurance to the extent necessary to do justice to the claimant. ${ }^{34}$ This suggests a more limited role for intention in estoppel - the only role, if any, will be presumptive in nature and linked to the issue of unconscionable conduct. Intention may help raise a presumption of a reasonable expectation of sharing on the part of the claimant and a further presumption that her contributions are being made towards realising that expectation, rather than as a gift or a loan. In that case, intention acts as a bridge between the inducement generated and the claimant's detrimental reliance, which together construct unconscionable conduct. Given the relevance of intention, albeit in different ways, in both the rights- and remedy-based approaches, we then have to ask ourselves how we should be (re)thinking intention and the interrelationship between intention and contributions, and whether mutuality of intention is necessary.

\section{(Re)thinking Intention and Contributions}

A significant aspect of the rights-based approach is the institutional nature of the constructive trust imposed as vindication of the claimant's pre-existing beneficial interest in the property. By contrast, remedy-based approaches like unconscionability and estoppel are aimed at providing a remedy that is sufficient to compensate the claimant and satisfy her equity. As such, it is uncertain whether constructive trust relief, rather than monetary compensation, will be granted in every case. The remedy-based approach therefore does not call for as clear a proprietary nexus between contributions and specific assets as does the rights-based approach. Consequently, it is not illogical that, in the latter, something more is needed than merely establishing an equity. The claimant would need to show that there is an intention to hold the property on trust, whether express or implied, and for her to share in the beneficial ownership of the property under that trust.

Under orthodox trusts analysis, the intention to hold the property on trust is not necessary in all types of trusts. In express trusts, it is the settlor's intention to declare a trust that is central to the creation of a valid trust. ${ }^{35}$ Intention equally has a role to play in resulting trusts. In the absence of evidence to the contrary, a presumed resulting trust will arise in favour of a claimant who makes direct financial contributions towards the acquisition of the property. The beneficial interest acquired will be proportionate to the contributions made. ${ }^{36}$ Constructive trusts, on the other hand, are traditionally

34 Greasley v Cooke [1980] 1 W.L.R. 1306; Coombes v Smith [1987] 1 F.L.R. 352; Banner Homes Group plc v Luff Developments Ltd [2000] Ch. 372; Gillett v Holt [2001] Ch. 210; Devlin v Northern Ireland Housing Executive [1982] N.I. 337; Norris v Walls [1997] N.I. 45.

35 Knight v Knight (1840) 3 Beav. 148 at p.173, per Lord Langdale M.R., where he stated that a valid trust would only arise where there were the "three certainties" intention, subject matter and objects.

36 These trusts are usually referred to as purchase money resulting trusts. See e.g. Cowcher v Cowcher [1972] 1 W.L.R. 425 (contribution towards mortgage repayments); Springette v Defoe [1992] 2 F.L.R. 388 (contribution by way of 


\section{Northern Ireland Legal Quarterly [Vol. 56, No. 1]}

seen as arising by operation of law. This implies, firstly, that the trust is imposed by the court based on established principles and not as a discretionary response; and secondly and more importantly, that the trust is not dependent on the parties' intentions. As Lord Browne-Wilkinson explains in Westdeutsche v Islington B.C.:

"Equity operates on the conscience of the owner of the legal interest. In the case of a trust, the conscience of the legal owner requires him to carry out the purposes for which the property was vested in him (express or implied trust) or which the law imposes on him by reason of his unconscionable conduct (constructive trust)." 37

Thus, under orthodox analysis, the parties' intentions are generally not relevant to the imposition of a constructive trust. Equity intervenes to enforce the trust because of the legal owner's conscience being affected, ${ }^{38}$ rather than the presence of some intention to share..$^{39}$

At first blush, this suggests that the Rosset trust creates two inconsistencies with orthodox analysis - not only is intention required for the imposition of a constructive trust, there must be mutuality of intention as well. It is, however, submitted that the only inconsistency in fact lies with the need for mutuality, not intention. The types of trusts being dealt with in Rosset in fact fall within the first category of cases noted by Lord Browne-Wilkinson. Glover and Todd, in their seminal piece, provide an excellent discussion on the question of whose intention is relevant to ground a claim for a beneficial share under the common intention trust. They argue that clearer distinctions should be made between intention, which can be unilateral, and common intention. ${ }^{40}$ In focusing on mutuality, Rosset causes confusion between not only the different types of trusts but also between contract and trusts law. Firstly, it is unclear which one of two roles intention undertakes - that is whether it is an intention to declare a trust or the meeting of minds to create legal relations in contractual analysis. Secondly, the focus on direct financial contributions towards the acquisition of the property also bears similarities to the resulting trust analysis.

Consequently, the current conceptualisation of intention in Rosset makes it difficult to locate the precise role of intention within this type of constructive trust. By referring to "common" intention, the courts have confused the analysis of intention with a contractual analysis, where the parties must demonstrate a shared intention - a meeting of minds - to hold the property on trust. Some commentators take issue with not only the mutuality element

discount in the purchase price); Tinsley v Milligan [1992] Ch. 310 and Lowson v Coombes [1999] Ch. 373 (contribution towards purchase price).

37 [1996] 2 All E.R. 961 at 988.

38 This basis for imposing a constructive trust is, to some extent, illustrated in cases such as Eves v Eves [1975] 1 W.L.R. 1338; Grant v Edwards [1986] Ch. 638; Ridgeway v Murray [1981] 7 N.I.J.B..

39 This approach can be seen in earlier cases, culminating in the narrower test adopted in Rosset. See e.g. Pettitt v Pettitt [1970] A.C. 777, Gissing v Gissing [1971] A.C. 886; Mcfarlane v Macfarlane [1972] N.I. 59; Allied Irish Banks Ltd. v McWilliams [1982] N.I. 156.

40 Glover and Todd, op. cit., n.5, at pp.328-329. 
but also with the intention element itself. Gardner, for instance, argues that intention is flawed as it focuses on the parties' thinking - something that is often absent and artificially constructed by the courts. ${ }^{41} \mathrm{He}$ therefore posits that doctrinal clarity can only be achieved by jettisoning intention and focusing instead on values such as trust and collaboration. ${ }^{42}$

Glover and Todd, however, argue that Gardner's reasons for rejecting the intention requirement are based on a narrow subjective conception of intention. In their view, an objective test is more appropriate as it focuses on whether a reasonable person would assume that the defendant's intention is to declare himself a trustee. ${ }^{43}$ The excuses given are thus capable of being construed as statements of intention to hold the property on trust for both parties and as explanations for why the defendant is prevented from doing so. ${ }^{44}$ This does not necessarily mean that any excuse or spurious statement will entitle the claimant to a beneficial interest under a constructive trust. ${ }^{45}$ As Megarry J. states in Re Kayford Ltd., ". . . the question is whether in substance a sufficient intention to create a trust has been manifested". ${ }^{46}$ The defendant's statements or conduct must point to an irrevocable and immediate intention to hold the property on trust. This leads Glover and Todd to reject the mutuality requirement but not intention. As they explain:

"what [the courts] should be looking for [under orthodox trusts analysis] is an intention to declare a trust, rather than to create a contract, for which common intention would obviously be necessary." 47

"Intention to share" in these cases is therefore essentially an intention to declare a trust; the party whose intention is relevant will thus depend on the type of trust one is dealing with. In that respect, Glover and Todd argue that, in the first category of the Rosset trust, reference to an express intention suggests that the trust is in fact an express trust, which is unenforceable due to lack of writing. ${ }^{48}$ It is, however, made enforceable as a result of the second condition of detrimental reliance by the claimant. This causes the defendant's conscience to be affected, thus triggering equity's intervention through the imposition of a constructive trust. The detrimental reliance requirement helps to carry the express trust outside the formalities

op. cit., n.5, at p. 265 .

42 ibid., at p.286.

43 Glover and Todd, op. cit., n.5, at pp.330-333.

44 See $e . g$. Eves v Eves (the excuse was that the plaintiff had not reached the age of twenty-one); Grant v Edwards (where the defendant claimed that it would prejudice her pending matrimonial proceedings); Hammond v Mitchell (where the defendant gave the excuse that the property had to be put in his name for tax reasons).

45 Moffat points out (at p.467) that common intention cannot be based on unarticulated assumptions of beneficial ownership and that the condition requires statements of a more specific nature. See Moffat, Trusts Law: Text and Materials ( $3^{\text {rd }}$ ed., 1999).

46 [1975] 1 W.L.R. 279 at 282.

47 Glover and Todd, op. cit., n.5, at p.328.

48 Law of Property Act 1925 (LPA), s.53(1)(b). 
requirement and render it enforceable. ${ }^{49}$ Accordingly, it is the defendant's intention that would be relevant. ${ }^{50}$

The second category (inferred intention), on the other hand, enables the claimant to acquire a beneficial interest by either a resulting or an express trust analysis. Glover and Todd argue that a presumed resulting trust analysis is apposite where the financial contributions are directly referable to the purchase of the property, e.g. payment towards the purchase price. Here it is the claimant's intention that is relevant; there is no need to establish either detrimental reliance or a constructive trust. However, they limit the use of the resulting trust to direct financial contributions towards the purchase price. Where other forms of direct and indirect contributions are made, they opine that the express trust analysis is more appropriate. ${ }^{51}$ In their view, it has the particular advantage of ensuring that the claimant's interest is fixed rather than left variable at the outset. However, in seeking to ensure beneficial shares are fixed at the outset, the distinction which they make between different types of direct financial contributions causes their analysis to become narrower than is necessary. There is no dispute that where the claimant has made direct financial contributions towards the purchase of the property, she has at the minimum a beneficial interest under a resulting trust. But the provision of such contributions does not, and should not, preclude the possibility of an intention on the part of the defendant to hold the property under an express rather than a strict resulting trust.

Applying the same logic to other forms of direct contributions, it is arguable that payment towards the purchase price should be equally capable of being dealt with using the concept of an express trust. This is borne out in cases like Midland Bank v Cooke, ${ }^{52}$ Drake v Whipp $^{53}$ and more recently, Oxley v Hiscock. ${ }^{54}$ In all three cases, the courts held that the direct financial contributions made by the claimant undoubtedly gave her a beneficial share in the property under a resulting trust. However, the provision of such contributions may also be evidence of an intention to share for the purposes of a constructive trust, which arguably is the express/constructive trust that Glover and Todd allude to. This reasoning is not inconsistent with the general thrust of their defendant-centred express/constructive trust analysis. As such, it is the defendant's intention that is relevant and the claimant's contributions merely facilitate the inference of such an intention. The issue then turns on whether the relevant intention may be inferred from the claimant making such contributions. ${ }^{55}$

49 See LPA, s.53(2). Rouchefoucauld v Boustead [1897] 1 Ch. 196; Bannister v Bannister [1948] 2 All E.R. 133.

50 op. cit., n.5, at pp.329-334.

51 ibid., at pp.334-337. These include direct contributions such as a discount in the purchase price and payment of mortgage instalments, even though such contributions have been held to give rise to a resulting trust in cases like Cowcher v Cowcher and Springette v Defoe.

52 [1995] 4 All E.R. 562.

53 [1996] 1 F.L.R. 826.

54 [2004] All E.R. (D) 48.

55 A distinction should further be made between inferring intention and determination of the extent of the parties' respective beneficial shares pursuant to that intention. It should be noted that, with respect to the latter, the Court of 
Leaving aside Gardner's objections to intention, his "trust and collaboration" approach may provide a useful basis for inferring intention in these situations. The presence of trust and collaboration may serve to raise the presumption of reasonable expectations to share the property as well as the defendant's (inferred) intention to hold the property for the benefit of both parties, rather than for his own individual benefit. The inclusion of values of trust and collaboration does not necessarily render intention, or the rightsbased approach, redundant. This highlights a gap in Gardner's analysis where a shift to trust and collaboration leads to the substitution of a rightsbased approach by a remedy-based (modified unjust enrichment) approach. ${ }^{56}$ Such a move places the claimant in a potentially weaker position since the remedy to be awarded is subject to the court's discretion and may not necessarily be proprietary in nature. Glover and Todd's analysis, on the other hand, offers greater potential for rationalising the constructive trust as being rights-based rather than a remedial response. This conceptualisation of the role of intention will provide inroads to resolving the existing problematic relationship between intention and contributions.

Under the present Rosset formulation, there is little scope for considering indirect contributions, except as evidence of detrimental reliance. On shifting the analysis away from mutuality and focusing instead on whether there is an intention to declare a trust, clearer distinctions may be made between constructive and resulting trusts. Furthermore, the test for determining whether the requisite intention is present should not be based solely on a subjective test but, rather, on both a subjective and an objective test. The adoption of such an approach would provide greater scope for the consideration of direct and indirect contributions under an express trust analysis. Given that a constructive trust is imposed to protect against inequities arising from a defendant reneging on an express trust, the issue of whether intention may be inferred should not therefore be limited to direct financial contributions. While contributions should be referable to the intention to share, they need not provide as clear a link to acquisition of the property as in resulting trusts. ${ }^{57}$ The extent to which intention may be inferred demonstrate the interplay between the relevant (objective) intention of the defendant and the making of contributions, whether direct or indirect, by the claimant. In such cases, the inference of an intention will depend on how the parties structure and organise their relationship, in particular the making of contributions, financial or non-financial. Arguably, Gardner's trust and collaboration approach might have some mileage here. It will enable us to move away from the referability rule and allow indirect

Appeal in Oxley v Hiscock did not follow the broad brush approach taken in Midland Bank v Cooke. It was held that, where an intention may be inferred from the direct contributions made but there is no evidence of any discussion or agreement between the parties regarding the extent of their respective beneficial interests, the better approach is that their shares should be determined on the basis of what is fair having regard to the whole course of dealing between them in relation to the property. Consequently, in the absence of evidence to support an intention of equal sharing, a fair division resulted in the claimant in Oxley being awarded a $40 \%$ share, which was equivalent to the proportion of her financial contributions towards the purchase of the property.

56 Gardner, op. cit., n.5, at pp.283-286.

57 Glover and Todd, op. cit., n.5, at pp.338-339. 
contributions to be taken into account in inferring the defendant's intention. On the basis of trust and collaboration, the way in which responsibilities and finances are organised by the parties will affect their reasonable expectations. This would provide a more realistic approach to addressing the question of whether there is, objectively, an intention for the shared home to be held on trust. More importantly, an evaluation of the parties' relationship from a trust and collaboration perspective provides the potential for the courts to adopt the principle of non-discrimination and the notion of substantive equality. This forms a fairer basis for determining the parties' intentions and reasonable expectations, one which will not discriminate against the party who undertakes a domestic role and the caring responsibilities in the relationship.

As has been argued elsewhere, while the HRA is unlikely to have direct horizontal effect in family property disputes, it will have some indirect horizontal effect. ${ }^{58}$ This is likely to be in the form of the courts taking into account values such as equality and non-discrimination enshrined in the Convention. Judicial comments in cases like White v White that "there is no place for discrimination between husband and wife and their respective roles" and "whatever the division of labour chosen ... or forced upon them by circumstances, fairness requires that this should not prejudice or advantage either party ... relating to the parties' contributions"59 may pave the way for the application of these principles in non-marital disputes over the shared home. With the emerging human rights discourse, the principles of equality and non-discrimination may provide further recognition of the need to reconceptualise the intention requirement. Future courts may possibly be more willing to give greater weight to the indirect financial and non-financial contributions of a claimant for the purposes of inferring intention. Again, we see the Family law courts taking a lead here. In Le Foe $\mathrm{v} L e F o e{ }^{60}$ the court was willing to accept that the wife's indirect financial contributions to the mortgage was sufficient to give rise to an inference of a sharing intent.

\section{CONCLUSION - THE WAY FORWARD}

This paper has argued that there are still some advantages to retaining the rights-based/common intention constructive trust. Although some commentators strongly advocate the common intention trust be jettisoned in favour of remedy-based approaches such as unconscionability and estoppel, there are reasons for cautioning against such a move. Notwithstanding the weaknesses of the current formulation of the common intention constructive trust, one of its clear advantages is its institutional nature. A rights-based approach means that the trust reinforces the claimant's property rights and provides her with a proprietary remedy without having to rely on the discretion of judges. Remedy-based approaches, on the other hand, focus on the prevention of unconscionable conduct. The latter, at present, have the added advantage of flexibility in terms of taking into account indirect contributions. However, being remedy-based, there are the disadvantages of being subject to judicial discretion and unpredictability in terms of the

58 Wong (2003) 11(2) F.L.S. 119.

59 [2001] 1 All E.R. 1 at 8-9, per Lord Nicholls.

60 [2001] All E.R. (D) 325. 
outcome and the type of remedy to be awarded. Moreover, intention remains a relevant factor in some remedy-based approaches, for example unconscionability. But our understanding of intention in those situations is substantially different from that under a rights-based approach.

The key difficulties of the common intention approach lies in the confusion caused by Rosset and in its failing to clarify the different types of trusts at play in these cases and the role of intention in each of the separate situations. Thus, the Law Commission's proposed solution - an expansion of the qualifying contributions to enable the inference of an intention - addresses some of the difficulties posed by Rosset but fails to provide a defensible argument for retaining the intention requirement. What is needed is the reconceptualisation of intention so as to bring greater coherence to the existing equitable principles. In that respect, certain conclusions are made. Firstly, we should move back to an analysis which is more congruent with constructive trust principles. In that respect, the "common intention" label should be abandoned and the intention requirement in both categories of the Rosset trust should mainly focus on whether the defendant objectively intends to hold the property on trust. Here, the objective test should indicate an irrevocable and immediate intention to hold the property on trust. It is this that sets the constructive trust in these situations apart from those imposed in other situations such as unconscionability and estoppel. The trust is institutional and not remedial in nature, as it is premised on the defendant's intention to declare an express, albeit unenforceable, trust.

Secondly, once we accept that it is the defendant's intention that is generally the relevant intention, it provides greater scope for intention to be inferred from a wider range of contributions. Unlike cases dealing with resulting trusts, there need not be as strong a proprietary nexus based on direct financial contribution towards the purchase price. The inclusion of a wider range of contributions, whether direct or indirect, financial or non-financial, may also in part be led by the emerging human rights culture in the UK, with the courts being more willing to apply the principle of non-discrimination and the notion of substantive equality. These principles may be bolstered by values like trust and collaboration, which will encourage judges to view relationships more holistically and move away from the existing discriminatory treatment of non-financial, especially domestic, contributions.

Last but not least, the constructive trust arises as a result of the claimant having acted to her detriment in reliance on that objective intention, thereby causing the defendant's conscience to be affected and triggering equity's intervention. It is the fact that the defendant's conscience is affected that forms an essential aspect of the constructive trust and the factor that triggers equity's response in these cases. On its own, the defendant's intention to hold the property on trust is insufficient for the claimant to ground a claim since the trust would be nothing more that an unenforceable express trust by reason of the formalities requirement.

Once we begin to reformulate the constructive trust principles along these lines, it will not only pave the way for greater coherency but also remove much of the existing confusion between this rights-based approach and other equitable remedy-based approaches. Moreover, the resolution of disputes over the shared home need not necessarily be a choice of accepting, or rejecting, one approach over the other. Each has its merits and would serve 
118 Northern Ireland Legal Quarterly [Vol. 56, No. 1]

to provide claimants with alternative litigation strategies. A total abandonment of a rights-based approach, however, will cause claimants to lose a powerful litigation strategy which entitles them to a proprietary remedy as of right. 